\title{
放牧对草地生态系统磷循环调控机制的研究进展 与展望
}

\author{
乌力吉 ${ }^{1,2}$, 李响 $^{2}$, 赵萌莉 ${ }^{1}$, 白永飞 ${ }^{2,3^{*}}$ \\ 1. 内蒙古农业大学草原与资源环境学院, 呼和浩特 010011 ; \\ 2. 中国科学院植物研究所植被与环境变化国家重点实验室, 北京 100093; \\ 3. 中国科学院大学资源与环境学院, 北京 100049 \\ * 联系人, E-mail: yfbai@ibcas.ac.cn \\ 2020-03-25 收稿, 2020-05-03 修回, 2020-05-06 接受, 2020-05-07 网络版发表 \\ 国家自然科学基金(31630010)资助
}

摘要 放牧是全球范围内草地生态系统最主要和最直接的利用方式. 磷 $(\mathrm{P})$ 是植物生长所必需的大量元素, 同时也 是草地初级生产力的关键限制性养分元素, 广泛参与植物的光合、呼吸等重要代谢过程. 放牧通过直接和间接作 用影响草地植物和土壤各组分的 $\mathrm{P}$ 含量和 $\mathrm{P}$ 库, 进而通过正负两种反馈影响生态系统的 $\mathrm{P}$ 循环. 目前, 国内外有关放 牧对草地 $\mathrm{P}$ 循环的影响机制, 特别是 $\mathrm{P}$ 循环的生物学过程和机制尚不十分清楚. 本文总结了有关放牧对植物和土壤 各组分 $\mathrm{P}$ 含量及 $\mathrm{P}$ 库的影响及其机制, 并对该领域的几个重要研究方向和函待回答的科学问题进行了展望. 未来研 究中需要重点关注的问题包括: (1) 土壤微生物量 $\mathrm{P}$ 组成沿不同放牧强度的变化, 以及放牧对土壤微生物 $\mathrm{P}$ 源和汇的 影响机制; (2) 放牧如何影响土壤磷酸酶的活性(磷酸单酯酶、磷酸二酯酶、三磷酸单酯水解酶等)进而调控土壤中 P的矿化过程; (3) 放牧如何调控P在植物-土壤-微生物系统中的转化过程; (4) 采用分子生物学和组学的手段, 揭示 土壤微生物在 $\mathrm{P}$ 盾环及生态系统功能中的作用, 以及放牧如何影响植物和根际微生物, 进而调控生态系统P循环; (5) 不同放牧强度如何影响植物多样性、菌根真菌多样性及两者之间的关系, 进而影响植物对 P的吸收和利用, 以 及地上和地下生物量P库; (6) 不同家畜种类的食性差异及其对磷循环的影响机制; (7) 其他植食动物(野生食草动 物、植食昆虫、啮齿动物、蚯蚂、植食性线虫等)在草地生态系统P循环中的作用; (8) 不同放牧强度如何调控生 态系统各营养级组分的 N:P化学计量关系, 进而影响 N、P循环之间的耦合关系.

关键词 放牧生态系统, 磷循环, 磷含量, 磷库, N:P比, 磷限制

草地是陆地生态系统的重要组成部分，世界草地 总面积为 52.5 亿公顷, 约占地球陆地总面积的 $40.5 \%$ (不 包括格陵兰岛和南极 ${ }^{[1]}$. 放牧是全球范围内草地生态 系统最主要和最直接的利用方式, 对生态系统功能和 服务的维持具有重要的调控作用 ${ }^{[2]}$. 据统计, 由于长期 超载放牧我国草地 $90 \%$ 发生了不同程度的退化, 其中重 度退化草地比例达 $60 \%$ 左右 ${ }^{[3]}$. 过度放牧引起的草地退 化使生态系统功能(如初级生产力、养分循环等)和服
务(如水土保持、碳固持)显著降低 ${ }^{[4,5]}$. 磷 $(\mathrm{P})$ 作为植物 生长和繁殖的必需元素, 广泛参与有机体的光合和呼 吸等代谢过程，同时也是组成DNA、RNA、ATP等生 物分子以及细胞核和细胞膜的关键元素，在生态系统 物质循环和能量流动过程中起到了重要作用 ${ }^{[6]}$.

生态系统养分循环包括生态系统的养分输人和输 出以及养分元素在生态系统内生物(植物、微生物和 消费者)和非生物组分之间的移动 ${ }^{[7]}$. 陆地生态系统中, 
植被生产力通常受 $\mathrm{N} 、 \mathrm{P}$ 或两者共同限制，N、P循环之 间的耦合关系非常密切 ${ }^{[7]}$. 近年来, 生态系统氮(N)循环 受到了广泛的重视, 研究人员开展了大量的研究工作. 然而, 同 $\mathrm{N}$ 盾环相比, $\mathrm{P}$ 循环的研究相对较少, 尤其是放 牧对草地 $\mathrm{P}$ 循环影响的研究十分有限 ${ }^{[8]}$. 例如, 早期研究 认为, 水分和氮是干旱、半干旱地区生态系统初级生 产力的主要限制因子 ${ }^{[9,10]}$, 但近年来一些研究发现, P似 乎比 $N$ 对初级生产力的限制作用更强 ${ }^{[8]}$. 大量研究表明, 施肥、氮沉降、种植固氮植物等人类活动的加剧, 加 速了陆地生态系统的 $\mathrm{N}$ 循环 ${ }^{[7,11]}$, 使土壤中 $\mathrm{N}$ 的含量及 其有效性增加 ${ }^{[12]}$, 进而使 $\mathrm{P}$ 的相对限制性增加 ${ }^{[8,13,14]}$. 然 而，与 $\mathrm{N}$ 循环不同， $\mathrm{P}$ 循环属于相对封闭的沉积型循环， 其周转时间为 $10^{7} \sim 10^{8}$ 年. 在成土过程中, 土壤中的 $\mathrm{P}$ 会 随着植物的利用和人类的开采而不断消耗. 因此, 从某 种意义上讲 $\mathrm{P}$ 属于地球上的不可再生资源, P必将取代 $\mathrm{N}$ 成为植物生长和生态系统功能和服务维持的主要限制 因子 ${ }^{[8,15]}$. 目前, 由于不合理的开发和利用已经造成P资 源的相对枯竭, 据初步估计在 21 世纪中叶地球上 $50 \%$ 的 廉价P将被耗竭 ${ }^{[16]}$.

草地生态系统中，放牧主要通过采食、践踏和粪 尿返还等方式影响养分循环过程 ${ }^{[17-22]}$. 在较短的时间 尺度, 磷循环主要发生在生态系统内植物、动物和土 壤组分之间, 植物、动物和土壤微生物的生理生态过 程控制着磷在土壤和生物体内的移动和形态转化 ${ }^{[7]}$. 目前已有的研究主要集中在放牧对草地土壤和植物 $\mathrm{P}$ 含量及 $\mathrm{P}$ 库的影响, 结果存在较大差异, 影响机制尚不 十分清楚(图1). 为此, 本研究在查阅相关文献的基础 上, 从三个方面对已有的研究进行总结, 并对未来研究 重点进行展望: (1) 放牧对草地生态系统P元素内外循
环的影响；(2) 从土壤P的垂直分布、输人与输出、土 壤侵蚀和空间异质性四个方面讨论放牧对土壤 $\mathrm{P}$ 含量 和P库的影响; (3) 放牧对不同组织水平(个体、物种、 植物功能群、群落)植物 $\mathrm{P}$ 含量和P库的影响机制; (4) 草地磷循环研究展望.

\section{1 放牧对草地生态系统磷元素内外循环的 影响}

植物在生长发育过程中所需的 $\mathrm{P}$ 主要来源于土壤, 但同 $\mathrm{C} 、 \mathrm{~N}$ 等元素相比, 土壤中的 $\mathrm{P}$ 含量很低, 仅占土壤 总质量的 $0.02 \% \sim 0.2 \%{ }^{[23]}$. 我国土壤P含量为 0.17 $1.11 \mathrm{~g} \mathrm{~kg}^{-1}$, 受成土母质的影响我国北方草地属于严重 缺P地区, 土壤中的P绝大部分以无效P的形式存在, 土 壤有机质是生态系统最主要的P库 ${ }^{[24,25]}$.

草地生态系统中, $\mathrm{P}$ 的输人方式主要包括大气干沉 降 ${ }^{[26]}$ 、母质风化 ${ }^{[27]}$ 和降水 ${ }^{[28]}$, 输出方式主要包括地表 径流 ${ }^{[29]}$ 、风蚀 ${ }^{[30,31]}$ 和淋溶 ${ }^{[22]}$ 等途径. 在放牧系统中, 畜 产品的 $\mathrm{N} 、 \mathrm{P}$ 输出往往是不可忽视的重要途径 ${ }^{[17,18]}$. 生 态系统中, $\mathrm{P}$ 最初都来源于岩石矿物的风化作用, 但该 过程十分缓慢, 一般通过风化作用进人生态系统的 $\mathrm{P}$ 为 $0.05 \sim 1.0 \mathrm{~kg} \mathrm{hm}^{-2} \mathrm{a}^{-1}$, 有些地区可以达到 $5.0 \mathrm{~kg} \mathrm{hm}^{-2} \mathrm{a}^{-1}$. 风化速率通常与土壤母质、气候、地形、植被覆盖等 非生物和生物因素有关, 生态系统中土壤风化主要是 风而非水的作用 ${ }^{[27]}$. 在干旱、半干旱草原, 水分是主要 的限制因子, 因此通过降雨、淋溶的方式输人和输出 生态系统的P均相对较少, 而大气干沉降和风蚀是影响 草地生态系统P输人和输出的关键因子 ${ }^{[30,33 \sim 35]}$. 研究表 明，干沉降和风蚀往往是同时发生的，因此土壤P的输 人和输出也同时发生, 它们共同受植被覆盖度和高

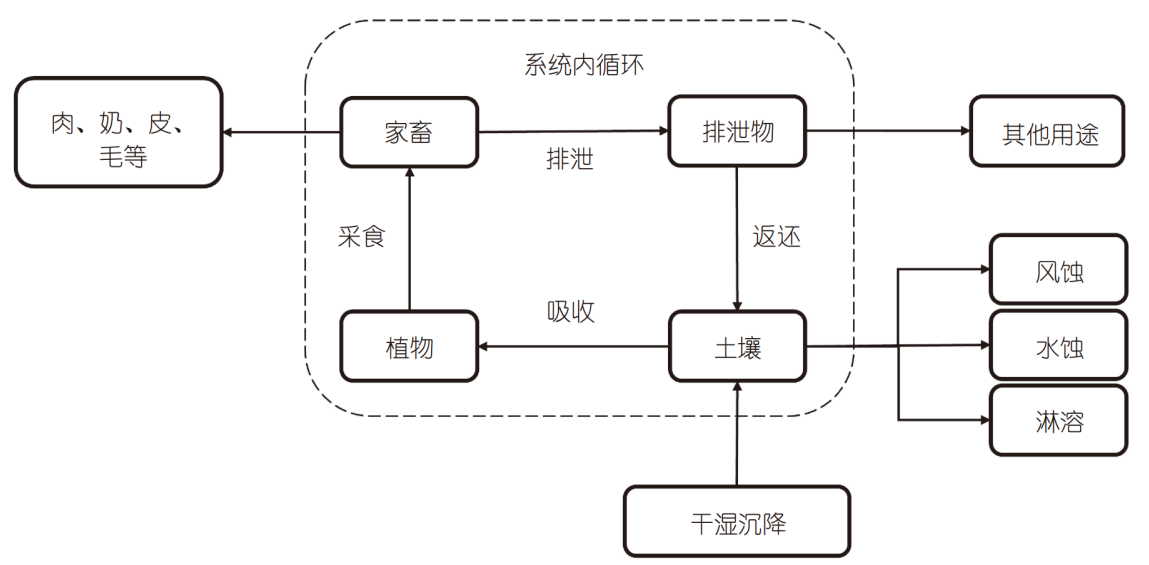

图 1 放牧对草地生态系统磷循环影响的概念图

Figure 1 A conceptual diagram for the influence of grazing on P cycle in grassland ecosystems 
度 ${ }^{[26]}$ 、地形 ${ }^{[31]}$ 、放牧强度等 ${ }^{[36]}$ 因素影响. 例如, 内蒙古 草原由于春季受到风的强烈影响, 干沉降可达 $7 \mathrm{~kg} \mathrm{P} \mathrm{ha} \mathrm{a}^{-1[37]}$, 有些地区甚至可以达到 $9 \mathrm{~kg} \mathrm{P} \mathrm{ha}^{-1} \mathrm{a}^{-1[38]}$, 其中放牧强度起到关键的调控作用, 甚至可以改变土壤沉降或侵蚀的方向 ${ }^{[30]}$. Zhou等人 ${ }^{[39]}$ 对全球443篇文献进行Meta分析发现，草地生态系统中 $\mathrm{P}$ 的输人和输出量分别为 $0.001 \sim 13.9$ 和0.001 12.7 kg P $\mathrm{ha}^{-1}$, 二者的变化范围大致相同. $\mathrm{He}$ 等人 ${ }^{[40]}$ 进一步研究 发现, 在全球尺度上, 放牧显著增加了植物叶片、茎、 根系、调落物P库, 使土壤P库增加 $3.6 \%$.

放牧对 $\mathrm{P}$ 在生态系统内循环的影响主要表现为: (1) 改变植物群落的物种组成, 植物与菌根真菌之间的互 惠共生关系, 影响植物对土壤P的吸收利用, 以及植物 对P的重吸收 ${ }^{[41-45] ;}$ （2) 改变群落生物量的大小及其在 地上/地下部分的分配比例、调落物的数量和质量, 以 及放牧家畜的粪尿返还, 影响土壤P的输人和家畜生物 量输出, 进而影响生态系统各组分 $\mathrm{P}$ 库的大小以及 $\mathrm{P}$ 循 环速率 ${ }^{[17,41,43,46]}$; (3) 改变小气候、光的有效性和土壤 水分状况, 影响土壤微生物活性, 进而影响土壤有机质 的矿化和P循环 ${ }^{[6,47 ~ 49]}$. 近期研究发现, 干湿交替增加了 土壤 $\mathrm{P}$ 的有效性，有利于干旱忍耐型植物对 $\mathrm{P}$ 的利用 ${ }^{[50]}$; (4)改变生态系统中植物-土壤动物-土壤微生物之间调 控与反馈关系、养分限制和养分平衡 ${ }^{[15,51]}$, 特别是 $\mathrm{P}$ 与 C、 $\mathrm{N}$ 的化学计量关系，以及 $\mathrm{P}$ 循环与 $\mathrm{C} 、 \mathrm{~N}$ 循环之间的 耦合关系 ${ }^{[14,52 \sim 54]}$.

\section{2 放牧对土壤磷的影响}

\section{1 放牧对土壤磷含量垂直分布的影响}

土壤P缺乏是我国北方草原面临的共性问题. 汪卫 卫 ${ }^{[55]}$ 对松嫩草地的研究发现, 没有放牧的草地, 土壤全 磷的垂直分布格局呈先降低后增加的趋势，表层土壤 的全P含量为 $0.27 \mathrm{~g} \mathrm{~kg}^{-1}$, 最小值出现在 $70 \mathrm{~cm}$ 土层, 全 $\mathrm{P}$ 含量仅为 $0.08 \mathrm{~g} \mathrm{~kg}^{-1}$; 放牧条件下, 只有重度放牧会降 低土壤表层全 $\mathrm{P}$ 含量, 轻度和中度放牧的草地土壤 $\mathrm{P}$ 含 量随土层深度的增加而降低. 李香真 ${ }^{[56]}$ 对内蒙古羊草 草原的研究发现, 放牧使0 100 cm的土壤P储量降低了 $21 \%$, P 储量随土层深度增加而降低. 李耀等人 ${ }^{[57]}$ 对内 蒙古典型草原的研究也得出了类似的结果, 不同土层 中全P含量均表现为禁牧 $>$ 自由放牧 $>$ 轮牧, 在不同利用 方式中P含量均随土层深度增加而降低. 郭颖 ${ }^{[58]}$ 对青藏 高原不同植被类型土壤表层全P含量的研究表明, 全P
含量为 $0.12 \sim 1.11 \mathrm{~g} \mathrm{~kg}^{-1}$, 草地、高寒草甸和高山草原 的土壤全P含量一般随土层深度的增加而降低. 尽管放 牧对不同草地类型土壤 $\mathrm{P}$ 含量和P库的影响目前仍然没 有一致性的结论，但放牧通过改变风蚀、水蚀、调落 物、植物根系分布、粪尿返还等，影响表层土壤微生 物活性以及植物和微生物对P的吸收和周转 ${ }^{[9,60]}$, 进而 影响表层土壤的 $\mathrm{P}$ 含量和 $\mathrm{P}$ 库. 特别是长期重度放牧, 使 表层土壤的风蚀和水蚀增加, 调落物显著降低, 植物根 系分布浅层化, 粪尿返还量显著增加 ${ }^{[26,41,46,61]}$.

放牧草地中，受植物残体、放牧家畜粪尿返还以 及土壤有机质长期积累的影响, 土壤有效 $\mathrm{P}$ (如Olsen $\mathrm{P}$ ) 含量一般随土层深度的增加而显著降低 ${ }^{[62]}$. 家畜排泄 出的 $\mathrm{P}$ 绝大部分以粪便的形式存在, 其 $\mathrm{P}$ 含量远远高于 饲草中的 $\mathrm{P}$ 含量. 例如, 绵羊粪便中的全 $\mathrm{P}$ 含量为 $8 \mathrm{~g} \mathrm{~kg}^{-1}$, 牛粪便中的全P含量为 $5.5 \mathrm{~g} \mathrm{~kg}^{-1}$; 同时, 新鲜 粪便中的 $\mathrm{P}$ 含量显著高于干燥粪便中P含量 ${ }^{[63]}$. 粪便中 的 $\mathrm{P}$ 大约 $20 \%$ 为植物可以利用的无机态 $\mathrm{P}$, 而粪便中的 有机态 $\mathrm{P}$ 则需要经过微生物分解后才能缓慢地被植物 利用 ${ }^{[63,64]}$. Baron等人 ${ }^{[46]}$ 对人工草地的研究发现, 由于 家畜的粪尿返还作用，放牧显著增加了表层土壤的可 提取 $\mathrm{P}$ 含量(extractable $\mathrm{P}$ concentration), $0 \sim 15 \mathrm{~cm}$ 土壤 的可提取 $\mathrm{P}$ 含量在重度放牧下最高, 中度放牧下次之, 轻度放牧下最低. 因此, 重度放牧下, 家畜的粪便返还 增加了 $\mathrm{P}$ 的流动, 进而加速了表层土壤的 $\mathrm{P}$ 循环.

\section{2 放牧对土壤磷含量及磷输入和输出的影响}

在放牧系统中，家畜对草地的利用驱动着物质循 环和能量流动, 放牧通过采食、粪尿排泄以及畜产品 的输出等方式改变了植物-土壤的反馈作用，对土壤产 生正、负两种反馈机制影响土壤P含量. 一些研究发 现, 围栏禁牧阻止了家畜采食, 减少了能量和养分从生 态系统的输出, 增加了土壤的P含量. 在物质输出方面, 由于植物固定了大量养分, 禁牧可以有效减少物质和 能量从土壤-植物系统到消费者的输出 ${ }^{[65]}$, 而放牧家畜 以皮、毛、肉、奶、粪尿等形式将 $\mathrm{N} 、 \mathrm{P}$ 输出生态系 统 ${ }^{[17,18]}$, 持续高强度的放牧增加了 $\mathrm{P}$ 的输出量和输出速 率, 降低了土壤号量及其 $\mathrm{P}$ 储量. 在物质输人方面, 放 牧通过改变输人系统的凋落物数量和质量进而减缓了 养分循环 ${ }^{[19]}$. 许多研究表明, 在干旱、半干旱草原, 放 牧对地上生物量和地下生物量均有显著的负效

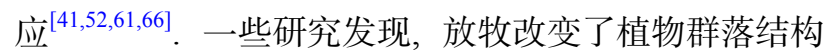
和物种组成 ${ }^{[5,41,67]}$, 显著降低了地上生物量的养分含 
量 $^{[68]}$, 进而对调落物和根系分解产生抑制作用, 减缓了 P返还生态系统的数量和速率. 放牧还可以通过植物土壤-家畜间的正反馈作用增加土壤的磷含量. 研究表 明, 放牧系统中, 家畜从生态系统中获取 $\mathrm{P}$, 但家畜未能 同化吸收的养分绝大部分都以粪尿的形式返还土 壤 ${ }^{[17,69]}$. 由于 $\mathrm{P}$ 的移动性差, 被固定后很少向土壤深层 迁移, 家畜排泄后 $\mathrm{P}$ 又重新与土壤中的 $\mathrm{Fe} 、 \mathrm{Al} 、 \mathrm{Ca}$ 等元 素结合形成难溶性络合物, 或吸附于土壤胶体中 ${ }^{[8]}$, 使 $\mathrm{P}$ 在土壤表层中富集, 增加了土壤表层的 $\mathrm{P}$ 含量. 李香 真 ${ }^{[56]}$ 研究认为, 放牧家畜的践踏作用使表层土壤容重 增加, 限制了水分和养分的垂直移动, 动物排泄物的输 人使表层土壤速效养分增加. 这些因素使根系向土壤 表层分配的比例增加, 表现为根系浅层化现象, 因此表 层土壤的有机碳、磷在一定的阶段内可以维持原有水 平或高于原有水平 ${ }^{[56]}$. 进一步研究发现, 尽管在干旱、 半干旱地区, 适度放牧增加了植物群落地上生物量 ${ }^{[70]}$ 和养分含量 ${ }^{[71]}$, 促进了土壤-植物间的正反馈作用 ${ }^{[19]}$, 而且适度的践踏可以加速调落物的破碎化，减少淍落 物的现存量, 增加分解的表面积 ${ }^{[72]}$, 加速P返还生态系 统的速率.

风蚀不仅破坏土壤的结构, 对草地初级生产力维 持具有负面影响, 同时也是引起草地退化的主要机 制 ${ }^{[31,73]}$. 在放牧系统中, 土壤侵蚀是导致表层土壤 $\mathrm{P}$ 含 量发生变化的主要因素 ${ }^{[35]}$. 放牧主要通过家畜采食影 响植被盖度和高度, 进而改变土壤风蚀和水蚀过程. 由 于受到风的强烈影响，我国北方地区土壤风蚀和干沉 降往往是同时发生的, 这两个过程很难分开 ${ }^{[26]}$, 放牧强 度对这两个过程起到关键的调控作用, 甚至可改变其 方向 ${ }^{[30]}$. 在放牧强度较低或禁牧状态下, 群落具有较高 的植被高度和盖度, 增加了地表的粗䊁度, 这不仅可以 有效地减少风蚀引起土壤侵蚀, 而且能够截获风沙中 高养分含量的土壤细砂。但重度放牧破坏了土壤团粒 结构和土壤结皮, 降低了植被高度和盖度, 造成了严重 的地表裸露, 同时增加了近地面的风速, 这些因素都会 加剧风蚀作用, 使土壤表层由养分含量低的粗砂组成, 降低了土壤P含量. $\mathrm{Li}$ 等人 ${ }^{[74]}$ 从能量角度解释了植被盖 度和群落结构对风蚀和土壤养分流失的影响, 他们发 现, 当植被盖度较低时, 发生土壤侵蚀的风速國值会降 低. 这是由于当土壤颗粒跃移过程发生后, 已经发生移 动的土壤颗粒将部分能量转移到土壤表层颗粒，有效 地降低了阈值风速. 同时, 植被盖度降低特别是草本植 物盖度的降低, 使植被对风的动力衰减作用降低, 导致
表层土壤风蚀加剧. 另外, 调落物输人减少和丧失使土 壤含水量降低, 导致表土对风蚀的敏感性增加 ${ }^{[74]}$. 因此, 过度放牧引起的植被盖度降低、群落物种组成改变 (如多年生禾草被一年生杂类草替代)、调落物减少, 是 导致干旱和半干旱草原表层土壤风蚀加剧、生态系统 $\mathrm{P}$ 净输出增加的主要原因.

一些学者认为, 放牧在短时间内对土壤P含量的影 响不大，而造成其含量差异的主要因素可能是空间异 质性 ${ }^{[75 \sim 77]}$. 家畜通过粪尿排泄、践踏和选择性采食等 方式改变土壤的空间异质性，但目前有关放牧对土壤 空间异质性的影响仍没有一致的结论 ${ }^{[75 ~ 79]}$. 一些研究 认为, 家畜的粪尿排泄对土壤养分的空间分布有直接 的作用 ${ }^{[77,80]}$. 例如, 绵羊为了避免牧草被粪尿污染通常 会在相对固定的区域排泄，因此在排泄物相对集中的 区域形成粪斑和尿斑 ${ }^{[81]}$, 植物可利用的 N、P在这些斑 块的土壤表层富集, 增加了土壤养分的空间异质性. 同 时，家畜的践踏作用直接或间接地改变了土壤的理化 性质和植被的分布格局，进而影响土壤N、P的空间异 质性. 适度的践踏通常可以增加土壤的空间异质性, 而 重度践踏则降低异质性 ${ }^{[82]}$. 家畜的选择性采食对土壤 养分(如N、P) 空间异质性的影响具有复杂性, 表现为 采食作用既可能增加也可能降低土壤养分的空间异质 性. 家畜的选择性采食减少了可食牧草的盖度和高度, 造成不同强度的采食斑块，形成了“肥岛效应”(island

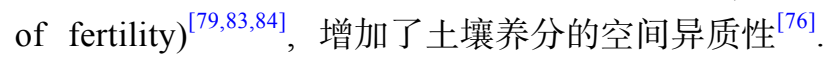
但如果家畜采食降低群落中非优势物种的多度, 使优 势物种分布更均匀，这可能造成土壤空间格局的同质 性 ${ }^{[85]}$. 然而, Burke等人 ${ }^{[79]}$ 对美国矮草草原的研究发现, 地形是影响土壤空间变异的主要因素, 而放牧和物种 则几乎没有影响. Kölbl等人 ${ }^{[31]}$ 对内蒙古典型草原研究 发现，放牧强烈影响着景观尺度上地形控制的土壤颗 粒迁移过程, 并对地上生物量和与生物量相关的土壤 特性具有强烈的影响. 上述研究表明, 长期放牧可能通 过选择性采食、践踏、粪尿排泄等方式改变不同土壤 斑块的生物、物理和化学属性, 进而影响斑块尺度的 $\mathrm{P}$ 含量和P循环.

\section{3 放牧对植物地上生物量磷含量和磷库的 影响}

草地生态系统中, 植物群落的养分含量受气候、 土壤、物种组成和放牧等生物和非生物因素的影

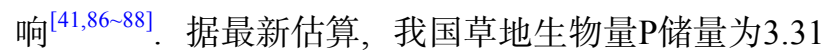


$\mathrm{Tg}$, 植物叶片平均 $\mathrm{P}$ 含量为 $1.27 \mathrm{~g} \mathrm{~kg}^{-1}$ (95\%的置信区间 为 $0.82 \sim 1.98 \mathrm{~g} \mathrm{~kg}^{-1}$ ), 根系平均 $\mathrm{P}$ 含量为 $0.69 \mathrm{~g} \mathrm{~kg}^{-1}$ ( $95 \%$ 的置信区间为 $0.42 \sim 1.13 \mathrm{~g} \mathrm{~kg}^{-1}$ ), 叶片 $\mathrm{N}: \mathrm{P}$ 平均为 $12.7^{[89]}$. 研究表明, 放牧通过改变草地生态系统的结构和功能 来影响养分循环 ${ }^{[18,41,90]}$. 例如, 放牧会改变群落的物种 组成和多样性 ${ }^{[90]}$, 物种的相对多度和 $\mathrm{P}$ 含量、 $\mathrm{P}$ 输人与 输出等影响植物 $\mathrm{P}$ 含量和地上生物量 $\mathrm{P}$ 库 ${ }^{[17,18,41,70,91]}$, 进 而影响生态系统P循环.

\section{1 放牧对植物个体和物种水平磷含量及磷库的 影响}

植物的资源利用策略、养分权衡分配、表型可塑 性等都会影响其P含量和P库, 放牧对植物的形态、物 候和生理等多方面具有重要的影响 ${ }^{[41,71,92]}$. $\mathrm{Li}$ 等人 ${ }^{[93]}$ 研 究了放牧对羊草(Leymus chinensis) 养分分配和个体大 小的影响发现，放牧显著增加了羊草茎和叶的P含量, 但降低了其叶茎比和个体P库，二者间存在显著的负相 关．这表明放牧改变了羊草个体水平 $\mathrm{P}$ 含量与 $\mathrm{P}$ 库之间 的权衡关系, 使养分更多地分配给光合器官, 导致了羊 草的矮小化. 生长稀释假说认为, 如果叶生物量的累积 增加大于养分获取量的增加, 养分含量将下降 ${ }^{[94]}$. 放牧 系统中, 家畜采食养分含量高的叶片组织, 植物为了完 成其生活史, 将更多的养分分配给叶片, 增加了叶片的 $\mathrm{P}$ 含量. 但在没有放牧的群落中, 植物生物量的增加导 致了P的稀释作用. 植物在无牧和放牧条件下养分分配 策略的改变，反映了草原植物同草食动物长期协同进 化过程中形成的植物个体水平上生长与维持之间的权 衡. 在物候方面，可食牧草被家畜采食后的再生，延迟 了植物的物候，而幼嫩组织的P含量显著高于成熟组 织 ${ }^{68]}$. 在物种水平, 近期研究发现, 长期自由放牧使典 型草原群落中具有高比根长、高细根比例、根鞘酸性 磷酸酯酶活性高的物种多度增加，这些物种具有较高 的P获取能力 ${ }^{[95]}$. Smith等人 ${ }^{[96]}$ 研究发现, 具有较低比根 面积和较高根系 $\mathrm{P}$ 含量的物种，其根系分解速率更快. 因此, 放牧引起的物种组成改变将影响植物群落水平 $\mathrm{P}$ 的吸收利用和周转, 以及 $\mathrm{P}$ 与碳、氮之间耦合关系.

\section{2 放牧对植物功能群水平磷含量和磷库的影响}

植物功能群(plant functional group)通常是指对特 定或相同环境因子的改变具有相同响应，在生态系统 中起相似作用的一类物种的组合. 植物功能群的变化 对生态系统功能和服务具有重要影响 ${ }^{[90,97]}$. Zheng 等
人 ${ }^{[71]}$ 对内蒙古锡林河流域的研究发现，放牧对植物 C、 N、P含量的影响随着组织水平的增加而增加(物 种-功能群-群落), 放牧改变了不同植物功能群的相对 生物量和 $\mathrm{P}$ 含量, 进而影响了植物群落地上生物量 $\mathrm{P}$ 库, 在植物功能群组成中，一、二年生植物属于资源获取 型策略(acquisitive resource-use strategy), 为了完成其 生活史，放牧后这类植物将更多的 N、P分配给地上组 织; 多年生丛生禾草则属于资源保守型策略(conservative resource-use strategy), 由于其适口性较差, 降低了 被家畜的采食, 因此其叶片 $\mathrm{N} 、 \mathrm{P}$ 含量变化不显著; 多年 生根茎型禾草属于中旱生植物, 具有较高的适口性和 耐牧性, 放牧后幼嫩器官取代了衰老器官, 增加了 $\mathrm{N}$ 、 $\mathrm{P}$ 向叶片的分配; 多年生杂类草在资源利用方式、放牧 耐受性等方面都介于一、二年生植物和多年生丛生禾 草之间，其对放牧的响应比较温和. Bai等人 ${ }^{[41]}$ 在蒙古 高原草原样带调查中也发现了类似的结论，放牧引起 植物功能群组成的改变是生态化学计量关系和生态系 统功能发生变化的主要机制。尽管放牧对草甸草原、 典型草原和荒漠草原不同植物功能群的影响大小和方 向并不完全一致，但放牧降低了这三类草原群落的地 上生物量和调落物P库，增加了草甸草原和典型草原地 下生物量P库, 降低了荒漠草原地下生物量P库. 对于草 甸草原, 放牧增加了地上生物量N:P比. 这些结果表明, 长期放牧加速了草甸草原的 $\mathrm{N} 、 \mathrm{P}$ 循环，但可能减缓了 典型草原和荒漠草原的P循环，进而改变了 $\mathrm{N} 、 \mathrm{P}$ 循环 之间的耦合关系.

\section{3 放牧对植物群落水平磷含量和磷库的影响}

在群落水平上，放牧主要通过促进和抑制养分循 环两个相反的机制影响植物的P含量和P循环. 促进养 分循环假说(accelerating nutrient cycling hypothesis)认 为, 家畜采食促进了养分含量高的耐牧物种的损失, 这 些物种可以通过快速吸收养分、提高相对生长率来进 行补偿性生长, 同时具有较高的组织养分含量, 这些变 化会引起调落物分解和养分周转加快，进而促进养分 循环 ${ }^{[20,21]}$. 而抑制养分循环假说(decelerating nutrient cycling hypothesis)则认为，家畜优先采食养分含量高 的植物，使木质素含量高、养分含量低、适口性差的 物种的优势度增加, 进而使凋落物分解速度降低, 减缓 了养分的周转和循环速率 ${ }^{[98]}$. Sitters等人 ${ }^{[99]}$ 研究发现, 放牧促进了北极冻原生态系统的 $\mathrm{N}$ 循环, 但增加了生物 量的P限制. 目前，大量的研究已经从资源有效性、调 
落物分解以及植物-土壤反馈等角度证实了放牧对植 物群落P含量或P库有正、负两种效应 ${ }^{[17,41,68,100 \sim 103]}$.

放牧除了改变植物群落水平的平均P含量外, 还可 以通过改变地上生物量, 进而影响生物量P库. 尽管有 关放牧对地上生物量的影响目前仍存在很大的争议, 但我国草地连续多年的放牧控制实验表明，在干旱、 半干旱草原, 中度和重度放牧对地上生物量均表现为 负效应 ${ }^{[11,54,67,104,105]}$. 这些结果与放牧优化假说相悖, 这 一方面可能与目前草地持续较高的放牧强度有关，另 一方面放牧能否促进植物生长主要与资源有效性有关. 在水分条件较好、养分利用率高、竞争低和早期放牧 的条件下, 植物会对放牧产生超补偿效应; 而在水分条 件差、养分有效性低、竞争强的环境下，植物对放牧 产生等补偿或欠补偿效应 ${ }^{[106]}$. 我国的干旱、半干旱草 原, 放牧历史悠久, 水分和养分有效性共同限制了放牧 对植物生长的促进作用, 因而长期放牧降低了群落地 上生物量 $\mathrm{P}$ 库, 特别是大部分的家畜粪尿滞留在畜圈 内, 不能返还到草地, 加上畜产品的输出, 加剧了生态 系统水平的 $\mathrm{P}$ 输出.

\section{4 放牧对植物根系磷含量和磷库的影响}

\section{1 放牧对根系形态和生理特征以及植物与丛枝菌 根真菌共生关系的影响}

根系不仅为植物地上部分的生长提供了水分和 $\mathrm{N} 、 \mathrm{P}$ 等养分, 同时根系是植物重要的养分库, 植物光合 作用固定的碳 $60 \%$ 以上被分配到地下根系中 ${ }^{[61]}$, 因此 根系动态对生态系统碳循环和养分循环具有重要的调 节作用 ${ }^{[66]}$. Bardgett等人 ${ }^{[103]}$ 认为, 在较短的时间尺度家 畜采食改变了植物根系分泌物和碳的分配模式, 在较 长的时间尺度放牧改变了植物的根系生物量及其形态, 二者共同影响了植物根系的 $\mathrm{P}$ 含量和 $\mathrm{P}$ 库动态. 植物可 以通过与丛枝菌根真菌(arbuscular mycorrhizal fungi,

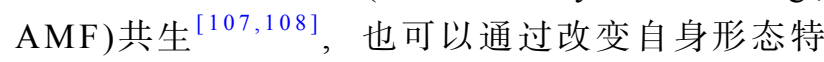
征 $^{[61,109,110]}$ 来提高其养分吸收能力. 研究表明, 植物所 需 $90 \%$ 的P来自 $\mathrm{AMF}^{[111]}, \mathrm{AMF}$ 在土壤中形成广泛的菌 丝网, 能够有效地获取P, 供给宿主植物 ${ }^{[12]}$. 碳限制假 说认为, 长期放牧减少了养分向地下部分的分配, 降低 了AMF的丰富度 ${ }^{[113]}$. 在资源相对丰富的条件下，放牧 增加了 $\mathrm{AMF}$ 的菌根侵染率及其频度, 维持了更高的生 物多样性和地上生产力; 反之, 放牧则降低了菌根侵染 率和频度，对多样性和生产力有一定的负效应 ${ }^{[114,115]}$.
同时，AMF的菌丝长度与放牧后资源有效性及土壤理 化性质有很强的相关性 ${ }^{[45]}$. 在生理上, 植物可以通过增 加表皮细胞质膜和P的亲和力以及释放有机酸、根系 分泌物等活化 $\mathrm{P}$, 增加 $\mathrm{P}$ 的吸收效率, 特别是在石灰质土 壤中, 酸化有利于释放Ca-P化合物中的 $\mathrm{P}^{[116]}$.

根系形态(根系直径、根毛长度等)对植物吸收和 利用 $\mathrm{P}$ 具有至关重要的作用 ${ }^{[117]}$. 周艳松等人 ${ }^{[118]}$ 对内蒙 古半干旱草原大针茅根系构型的研究发现，根系分叉 数、根表面积和总根长是影响大针茅根系对放牧响应 的主要指标, 随着放牧强度的增加, 大针茅根系趋于小 型化, 根表面积减少, 植物为了更好地适应环境会分叉 产生新的侧根吸收养分和水分. 此外, 重度放牧降低了 羊草的总根长、根表面积、根尖数等根系性状，抑制 了根系的吸收作用 ${ }^{[119]}$.

\section{2 放牧对根系生物量和地下生物量磷库的影响}

代谢理论和植物生物量分配理论可以解释放牧后 根系生物量的变化 ${ }^{[120,121]}$. 放牧通过改变植物光合产物 向地上和地下器官的分配, 使根系生物量及其占总生 物量的比例发生变化, 进而影响地下生物量P库和生态 系统P循环. 研究表明, 放牧对草地地下生物量的影响 主要与气候条件、放牧强度、放牧时间和土壤条件有 关. 在干旱、半干旱地区, 大部分研究认为, 放牧对根 系生物量有显著的负效应 ${ }^{[61,66,71,122]}$. Gao等人 ${ }^{[61]}$ 对半干 旱典型草原的研究发现, 同不放牧的围封群落相比, 放 牧显著降低了群落地下总生物量、活根生物量和净地 下初级生产力, 但对根系周转速率没有显著影响. 其中, 重度放牧使群落地下总生物量降低了 $37 \%$, 活根生物量 降低了 $56 \%$, 地下净初级生产力降低了 $36 \%$. Yan等 人 ${ }^{[104]}$ 基于全国草地的Meta分析表明，同全球草地的均 值相比，放牧对我国草地地下生物量具有很大的负效 应, 这种负效应主要来源于重度放牧草地. 这表明, 重 度放牧对地下生物量P库具有负效应. 放牧降低了植物 地上生物量, 导致光合产物更多地分配给植物地上器 官, 促进其补偿性生长, 导致植物以牺牲地下部分为代 价 ${ }^{[123]}$. 此外, 由于家畜的选择性采食, 重度放牧降低了 禾本科植物的丰富度, 改变了物种共存, 进而改变了地 下生物量 ${ }^{[124]}$ 及其P库. 上述研究表明, 长期过度放牧引 起的根系生物量(包括活根和死根)对土壤有机质的输 人减少, 可能会降低土壤微生物的活性, 如酸性和碱性 磷酸单酯酶 (phosphomonoesterase)活性, 导致土壤有机 P矿化速率的降低, 进而减缓生态系统P循环. 但也有一 
些研究发现, 放牧显著提高了土壤微生物的活性, 促进 了土壤有机质的分解过程, 进而可能加速生态系统P循 环 ${ }^{[17,125,126]}$.

\section{5 草地磷循环研究展望}

草地生态系统中, 放牧家畜是最主要消费者, 对生 态系统的P循环起着关键的调控作用. 尽管放牧对植物 和土壤P的影响已有大量相关报道, 但是大部分研究只 关注了放牧对土壤、植物或微生物组分中某一方面或 几方面的影响, 很少从整个生态系统水平研究放牧对 植物、土壤和微生物 $\mathrm{P}$ 库及 $\mathrm{P}$ 循环的影响, 特别是有关 $\mathrm{P}$ 循环关键生物过程及其机制的研究亟待加强 ${ }^{[6,60,127]}$. 因 此, 未来需要更多地关注家畜-植物-土壤(包括土壤动 物和土壤微生物)等多营养级的研究，以及放牧强度、

气候、地形、土壤和植物群落结构与组成如何影响 $\mathrm{P}$ 循环的关键生物过程(图2). 例如, 草地生态系统中, 土 壤微生物量 $\mathrm{P}$ 可达土壤全P的 $7.5 \%$, 其周转时间仅为几 个月, 土壤微生物作为 $\mathrm{P}$ 的源和汇, 对草地土壤 $\mathrm{P}$ 循环关 键过程(如P的矿化和固定)具有重要的调控作用 ${ }^{[6]}$. 然
而，有关放牧如何调控土壤微生物(如细菌、古菌、腐 生真菌)参与的P循环过程研究仍较薄弱, 其具体的生 物学机制尚不清楚 ${ }^{[6,19,111,113,115]}$.

植物多样性与微生物多样性和生态系统功能之间 关系是近年来生态学研究的一个热点领域 ${ }^{[128]}$. 植物-根 际微生物互惠共生促进 $\mathrm{P}$ 吸收利用假说认为, 丛枝菌根 真菌对植物多样性和生态系统功能的维持具有极其重 要的贡献. AMF的多样性及其与植物根系间的互惠共 生关系决定了草地群落的物种多样性, 这是因为 $\mathrm{AMF}$ 多样性的增加显著地增加了土壤中的菌丝长度, $\mathrm{AMF}$ 菌丝与植物根系形成的共生体大大延伸了植物根系的 吸收范围, 增加了植物对土壤养分特别是P的吸收利用, 进而增加了草地初级生产力和稳定性 ${ }^{[107,111]}$. 一些研究 表明，AMF与植物根系间的互惠共生关系有利于增强 寄主植物对放牧的忍耐性，但也有研究得出截然相反 的结论 ${ }^{[113,129]}$.

基于上述分析，放牧对草地 $\mathrm{P}$ 循环影响机制研究中 亟待回答的科学问题包括: (1) 土壤微生物量P的组成 (核酸、磷脂类、细胞质无机P和有机P、多磷酸盐)和

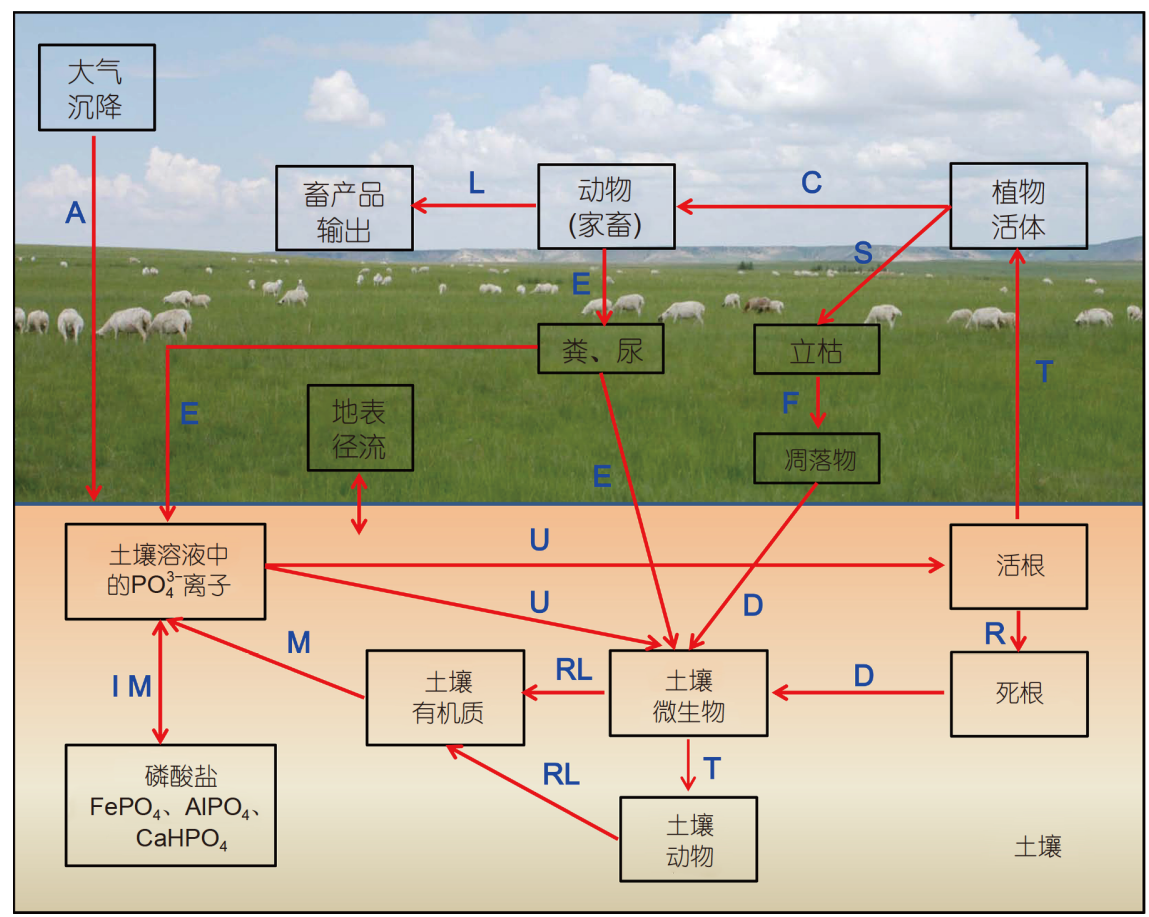

图 2 (网络版彩色)放牧对草地生态系统P库和P循环关键生物过程的调控机制. A, 大气湿沉降; C, 食草动物采食; D, 分解; E, 排泄物输出; F, 调落 物脱落; $\mathrm{L}$, 家畜移出; $\mathrm{M}$, 净矿化; R, 根系死亡; $\mathrm{S}$, 植物地上部分衰老和死亡; $\mathrm{T}$, 净转移; $\mathrm{U}$, 根系吸收; RL, 土壤动物和微生物释放; IM, 固定与活化 Figure 2 (Color online) Mechanisms underlying the effects of grazing on P pools and key biological processes of P cycling in grassland ecosystems. A, atmospheric wet deposition; C, consumption by herbivores; D, decomposition; E, urine and faces excretion; F, litter fall; L, livestock removal; M, net mineralization; R, root death; S, shoot senescence and death; T, net translocation; U, uptake by roots; RL, release by soil fauna and microbes; IM, immobilization and mobilization 
含量随不同放牧强度的变化, 以及放牧对土壤微生物 $\mathrm{P}$ 源和汇的影响机制 ${ }^{[130]}$; (2) 放牧如何影响土壤磷酸酶的 活性，包括磷酸单酯酶(phosphomonoesterases)、磷酸二 酯酶(phosphodiesterases)、三磷酸单酯水解酶(triphosphoric monoester hydrolases)及作用于含磷酰基酸酐和 $\mathrm{P}-\mathrm{N}$ 键的酶类, 进而调控土壤中P的矿化过程 ${ }^{[131]}$; (3) 放 牧如何调控P在植物-土壤-微生物系统中的转化过程, 包括: 植物和微生物对 $\mathrm{P}$ 的吸收, 植物根系和微生物分泌 物引起的土壤固相中无机 $\mathrm{P}\left(\mathrm{H}_{3} \mathrm{PO}_{4} 、 \mathrm{H}_{2} \mathrm{PO}_{4}^{-} 、 \mathrm{HPO}_{4}{ }^{2-}\right.$ 和 $\mathrm{PO}_{4}{ }^{3}$ ) 的释放, 植物残体向土壤中释放的无机 $\mathrm{P}$, 以及微 生物和有机质矿化引起的无机 $\mathrm{P}$ 释放等 ${ }^{[132]}$; (4) 采用分 子生物学和组学的手段在多大程度上能够帮助我们深 人理解土壤微生物在P循环及生态系统功能中的重要作
用，以及放牧如何影响植物和根际微生物，进而调控生 态系统P循环的生物过程 ${ }^{[133]}$; (5) 不同放牧强度如何影 响植物多样性、AMF多样性及两者之间的关系, 进而影 响植物对P的吸收和利用，以及地上和地下生物量P库; (6) 已有研究中, 放牧家畜类型比较单一 ${ }^{[17]}$ ，未来研究 中应关注不同家畜种类的食性差异对 $\mathrm{P}$ 循环的影响机 制; (7) 其他植食动物, 包括野生食草动物(如黄羊、藏 羚羊)、植食昆虫(如蝗虫)、啮齿动物、蚯蚓、植食性 线虫等在草地生态系统P循环中的作用 ${ }^{[134,135]} ;(8)$ 多数 情况下，草地生态系统中 $\mathrm{N}$ 和 $\mathrm{P}$ 循环是耦合在一起 的 ${ }^{[60,127]}$. 因此, 不同放牧强度如何调控生态系统各营养 级组分的 $\mathrm{N}: \mathrm{P}$ 化学计量关系, 进而影响 $\mathrm{N}$ 和P循环之间的 耦合关系, 也是未来研究中的一个新的增长点.

\section{参考文献}

1 White R P, Murray S, Rohweder M. Pilot Analysis of Global Ecosystems: Grassland Ecosystems. Washington DC: World Resources Institute, 2000

2 Asner G P, Elmore A J, Olander L P, et al. Grazing systems, ecosystem responses, and global change. Annu Rev Environ Resour, 2004, 29: 261299

3 Ministry of Environmental Protection of People's Republic of China. The 2005 Report on the State of the Environment of China (in Chinese) Beijing: Ministry of Environmental Protection of People’s Republic of China, 2006 [中华人民共和国环境保护部. 中国环境状况公报 2005. 北 京: 中华人民共和国环境保护部, 2006]

4 Bai Y F, Huang J H, Zheng S X, et al. Drivers and regulating mechanisms of grassland and desert ecosystem services (in Chinese). Acta Phytoecol Sin, 2014, 38: 93-102 [白永飞, 黄建辉, 郑淑霞, 等. 草地和荒漠生态系统服务功能的形成与调控机制. 植物生态学报, 2014, 38: 93-102]

5 Davidson K E, Fowler M S, Skov M W, et al. Livestock grazing alters multiple ecosystem properties and services in salt marshes: A metaanalysis. J Appl Ecol, 2017, 54: 1395-1405

6 Bünemann E K, Oberson A, Frossard E. Phosphorus in Action: Biological Processes in Soil Phosphorus Cycling. Berlin, Heidelberg: SpringerVerlag, 2011

7 Chapin F S III, Matson P A, Vitousek P M. Principles of Terrestrial Ecosystem Ecology. 2nd ed. New York: Springer, 2011

8 Vitousek P M, Porder S, Houlton B Z, et al. Terrestrial phosphorus limitation: Mechanisms, implications, and nitrogen-phosphorus interactions Ecol Appl, 2010, 20: 5-15

9 Hooper D, Johnson L. Nitrogen limitation in dryland ecosystems: Responses to geographical and temporal variation in precipitation. Biogeochemistry, 1999, 46: 247-293

10 Bai Y F, Wu J G, Xing Q, et al. Primary production and rain use efficiency across a precipitation gradient on the Mongolia Plateau. Ecology, 2008, 89: 2140-2153

11 Schlesinger W H. On the fate of anthropogenic nitrogen. Proc Natl Acad Sci USA, 2009, 106: 203-208

12 Greaver T L, Clark C M, Compton J E, et al. Key ecological responses to nitrogen are altered by climate change. Nat Clim Change, 2016, 6: 836843

13 Zhan S H, Wang Y, Zhu Z C, et al. Nitrogen enrichment alters plant N:P stoichiometry and intensifies phosphorus limitation in a steppe ecosystem. Environ Exp Bot, 2017, 134: 21-32

14 Marklein A R, Houlton B Z. Nitrogen inputs accelerate phosphorus cycling rates across a wide variety of terrestrial ecosystems. New Phytol, 2012, 193: 696-704

15 Elser J J, Andersen T, Baron J S, et al. Shifts in lake N:P stoichiometry and nutrient limitation driven by atmospheric nitrogen deposition. Science, 2009, 326: 835-837

16 Peñuelas J, Poulter B, Sardans J, et al. Human-induced nitrogen-phosphorus imbalances alter natural and managed ecosystems across the globe. Nat Commun, 2013, 4: 2934

17 Chaneton E J, Lemcoff J H, Lavado R S. Nitrogen and phosphorus cycling in grazed and ungrazed plots in a temperate subhumid grassland in 
Argentina. J Appl Ecol, 1996, 33: 291-302

18 Giese M, Brueck H, Gao Y Z, et al. N balance and cycling of Inner Mongolia typical steppe: A comprehensive case study of grazing effects. Ecol Monogr, 2013, 83: 195-219

19 Bardgett R D, Wardle D A. Herbivore-mediated linkages between aboveground and belowground communities. Ecology, 2003, 84: 2258-2268

20 McNaughton S J. Ecology of a grazing ecosystem: The Serengeti. Ecol Monogr, 1985, 55: 259-294

21 Frank D A, Evans R D. Effects of native grazers on grassland N cycling in Yellowstone National Park. Ecology, 1997, 78: 2238-2248

22 Zhou G Y, Zhou X H, He Y H, et al. Grazing intensity significantly affects belowground carbon and nitrogen cycling in grassland ecosystems: A meta-analysis. Glob Change Biol, 2017, 23: 1167-1179

23 Qin S J, Liu J S, Wang G P. Mechanism of phosphorus availability changing in soil (in Chinese). Chin J Soil Sci, 2006, 37: 1012-1016 [秦胜金, 刘景双, 王国平. 影响土壤磷有效性变化作用机理. 土壤通报, 2006, 37: 1012-1016]

24 Lu R K. General status of nutrients (N, P, K) in soils of China (in Chinese). Acta Pedol Sin, 1989, 26: 280-286 [鲁如坤. 我国土壤氮、磷、钾的 基本状况. 土壤学报, 1989, 26: 280-286]

25 Lai L, Hao M D, Peng L F. Development of researches on soil phosphorus (in Chinese). Res Soil Water Conserv, 2003, 10: 65-67 [来璐, 郝明德, 彭令发. 土壤磷素研究进展. 水土保持研究, 2003, 10: 65-67]

26 Hoffmann C, Funk R, Wieland R, et al. Effects of grazing and topography on dust flux and deposition in the Xilingele grassland, Inner Mongolia. J Arid Environ, 2008, 72: 792-807

27 Newman E I. Phosphorus inputs to terrestrial ecosytems. J Ecol, 2006, 83: 713-726

28 López-hernandez D, García M, Niño M. Input and output of nutrients in a diked flooded savanna. J Appl Ecol, 1994, 31: 303-312

29 Green V S, Dao T H, Stone G, et al. Bioactive phosphorus loss in simulated runoff from a phosphorus-enriched soil under two forage management systems. Soil Sci, 2007, 172: 721-732

30 Hoffmann C, Funk R, Li Y, et al. Effect of grazing on wind driven carbon and nitrogen ratios in the grasslands of Inner Mongolia. Catena, 2008, 75: 182-190

31 Kölbl A, Steffens M, Wiesmeier M, et al. Grazing changes topography-controlled topsoil properties and their interaction on different spatial scales in a semi-arid grassland of Inner Mongolia, P.R. China. Plant Soil, 2011, 340: 35-58

32 Chardon W J, Aalderink G H, van der Salm C. Phosphorus leaching from cow manure patches on soil columns. J Environ Qual, 2007, 36: 17-22

33 Okin G S, Mahowald N, Chadwick O A, et al. Impact of desert dust on the biogeochemistry of phosphorus in terrestrial ecosystems. Glob Biogeochem Cycle, 2004, 18: GB2005

34 Tsukuda S, Sugiyama M, Harita Y, et al. Atmospheric phosphorus deposition in Ashiu, Central Japan - Source apportionment for the estimation of true input to a terrestrial ecosystem. Biogeochemistry, 2006, 77: 117-138

35 Zhao H L, Yi X Y, Zhou R L, et al. Wind erosion and sand accumulation effects on soil properties in Horqin Sandy Farmland, Inner Mongolia. CATENA, 2006, 65: 71-79

36 Zhao Y, Peth S, Krümmelbein J, et al. Spatial variability of soil properties affected by grazing intensity in Inner Mongolia grassland. Ecol Model, 2007, 205: 241-254

37 Li F. Wind erosion and airborne dust deposition in farmland during spring in the Horqin Sandy Land of eastern Inner Mongolia, China. Soil Tillage Res, 2004, 75: 121-130

38 Yan Y C, Xu X L, Xin X P, et al. Effect of vegetation coverage on aeolian dust accumulation in a semiarid steppe of northern China. Catena, 2011, 87: $351-356$

39 Zhou Q L, Daryanto S, Xin Z, et al. Soil phosphorus budget in global grasslands and implications for management. J Arid Environ, 2017, 144: 224-235

40 He M, Zhou G Y, Yuan T F, et al. Grazing intensity significantly changes the C:N:P stoichiometry in grassland ecosystems. Glob Ecol Biogeogr, 2020, 29: 355-369

41 Bai Y F, Wu J G, Clark C M, et al. Grazing alters ecosystem functioning and C:N:P stoichiometry of grasslands along a regional precipitation gradient. J Appl Ecol, 2012, 49: 1204-1215

42 Faghihinia M, Zou Y, Chen Z, et al. The response of grassland mycorrhizal fungal abundance to a range of long-term grazing intensities. Rhizosphere, 2020, 13: 100178

43 Zhang T R, Li F Y, Shi C J, et al. Enhancement of nutrient resorption efficiency increases plant production and helps maintain soil nutrients under summer grazing in a semi-arid steppe. Agric Ecosyst Environ, 2020, 292: 106840

44 Lü X T, Freschet G T, Kazakou E, et al. Contrasting responses in leaf nutrient-use strategies of two dominant grass species along a 30-yr temperate steppe grazing exclusion chronosequence. Plant Soil, 2015, 387: 69-79

45 Ren H Y, Gui W Y, Bai Y F, et al. Long-term effects of grazing and topography on extra-radical hyphae of arbuscular mycorrhizal fungi in semiarid grasslands. Mycorrhiza, 2018, 28: 117-127 
46 Baron V S, Dick A C, Mapfumo E, et al. Grazing impacts on soil nitrogen and phosphorus under Parkland pastures. J Rang Manag, 2001, 54: 704-710

47 Faghihinia M, Zou Y, Chen Z, et al. Environmental drivers of grazing effects on arbuscular mycorrhizal fungi in grasslands. Appl Soil Ecol, 2020, 153: 103591

48 Shan Y, Chen D, Guan X, et al. Seasonally dependent impacts of grazing on soil nitrogen mineralization and linkages to ecosystem functioning in Inner Mongolia grassland. Soil Biol Biochem, 2011, 43: 1943-1954

49 Cole C V, Innis G S, Stewart J W B. Simulation of phosphorus cycling in semiarid grasslands. Ecology, 1977, 58: 1-15

50 Bünemann E K, Keller B, Hoop D, et al. Increased availability of phosphorus after drying and rewetting of a grassland soil: Processes and plant use. Plant Soil, 2013, 370: 511-526

51 Frank D A. Ungulate and topographic control of nitrogen: Phosphorus stoichiometry in a temperate grassland; soils, plants and mineralization rates. Oikos, 2008, 117: 591-601

52 Chen D M, Zheng S X, Shan Y M, et al. Vertebrate herbivore-induced changes in plants and soils: Linkages to ecosystem functioning in a semiarid steppe. Funct Ecol, 2013, 27: 273-281

53 Chen T, Christensen M, Nan Z B, et al. The effects of different intensities of long-term grazing on the direction and strength of plant-soil feedback in a semiarid grassland of Northwest China. Plant Soil, 2017, 413: 303-317

54 Wang B, Wu L J, Chen D M, et al. Grazing simplifies soil micro-food webs and decouples their relationships with ecosystem functions in grasslands. Glob Change Biol, 2020, 26: 960-970

55 Wang W W. Spatial patterns of soil nutrients and their response to grazing disturbance over the Songnen meadow steppes of NE China (in Chinese). Master Dissertation. Changchun: Northeast Normal University, 2007 [汪卫卫. 松嫩草地土壤养分空间格局特征及其对放牧干扰的 响应. 硕士学位论文. 长春: 东北师范大学, 2007]

56 Li X Z. ffects of grazing on phosphorus stock and forms in chestnut soil (in Chinese). Acta Pratacul Sin, 2001, 10: 28-32 [李香真. 放牧对暗栗钙 土磷的它量和形态的影响. 草业学报, 2001, 10: 28-32]

57 Li Y, Wei Z J, Liu H M, et al. Effects of different grazing regimes on total phosphorus and available phosphorus in a typical steppe (in Chinese). Inn Mong Pratacul, 2010, 22: 4-6 [李耀, 卫智军, 刘红梅, 等. 不同放牧制度对典型草原土壤中全磷和速效磷的影响. 内蒙古草业, 2010, 22: 4-6]

58 Guo Y. Distribution characteristics and influencing factors of soil phosphorus under different vegetation types in the Qinghai-Tibet Plateau (in Chinese). Master Dissertation. Tianjin: Tianjin Normal University, 2017 [郭颖. 青藏高原不同植被类型土壤磷分布特征及影响因素. 硕士学位 论文. 天津: 天津师范大学, 2017]

59 Rumpel C, Creme A, Ngo P T, et al. The impact of grassland management on biogeochemical cycles involving carbon, nitrogen and phosphorus. J Soil Sci Plant Nutr, 2015, 15: 353-371

60 Jouany C, Cruz P, Daufresne T, et al. Biological phosphorus cycling in grasslands: Interactions with nitrogen. In: Bünemann E K, Oberson A, Frossard E, eds. Phosphorus in Action: Biological Processes in Soil Phosphorus Cycling. New York: Springer. 2011

61 Gao Y Z, Giese M, Lin S, et al. Belowground net primary productivity and biomass allocation of a grassland in Inner Mongolia is affected by grazing intensity. Plant Soil, 2008, 307: 41-50

62 Haygarth P M, Hepworth L, Jarvis S C. Forms of phosphorus transfer in hydrological pathways from soil under grazed grassland. Eur J Soil Sci, 1998, 49: 65-72

63 McDowell R W, Stewart I. Phosphorus in fresh and dry dung of grazing dairy cattle, deer, and sheep. J Environ Qual, 2005, 34: 598-607

64 Heady H F, Child R D. Rangeland Ecology and Management. Boulder, Colorado: Westview Press, 1994

65 Wu G L, Du G Z, Liu Z H, et al. Effect of fencing and grazing on a Kobresia-dominated meadow in the Qinghai-Tibetan Plateau. Plant Soil, 2009, 319: $115-126$

66 Bai W M, Fang Y, Zhou M, et al. Heavily intensified grazing reduces root production in an Inner Mongolia temperate steppe. Agric EcoSyst Environ, 2015, 200: 143-150

67 Wan H W, Bai Y F, Schönbach P, et al. Effects of grazing management system on plant community structure and functioning in a semiarid steppe: Scaling from species to community. Plant Soil, 2011, 340: 215-226

68 Li C L, Hao X Y, Willms W D, et al. Effect of long-term cattle grazing on seasonal nitrogen and phosphorus concentrations in range forage species in the fescue grassland of southwestern Alberta. Z Pflanzenernähr Bodenk, 2010, 173: 946-951

69 Haynes R J, Williams P H. Nutrient Cycling and Soil Fertility in the Grazed Pasture Ecosystem. San Diego: Elsevier Academic Press Inc, 1993

70 Li W H, Xu F W, Zheng S X, et al. Patterns and thresholds of grazing-induced changes in community structure and ecosystem functioning: Species-level responses and the critical role of species traits. J Appl Ecol, 2017, 54: 963-975

71 Zheng S X, Ren H Y, Li W H, et al. Scale-dependent effects of grazing on plant C:N:P stoichiometry and linkages to ecosystem functioning in the Inner Mongolia grassland. PLoS One, 2012, 7: e51750 
72 Hou F J, Chang S H, Yu Y W, et al. A review on trampling by grazed 1 ivestock (in Chinese). Acta Ecol Sin, 2004, 24: 784-789 [侯扶江, 常生华, 于应文, 等. 放牧家畜的践踏作用研究评述. 生态学报, 2004, 24: 784-789]

73 Steffens M, Kölbl A, Giese M, et al. Spatial variability of topsoils and vegetation in a grazed steppe ecosystem in Inner Mongolia (PR China). J Plant Nutr Soil Sci, 2009, 172: 78-90

74 Li J, Okin G S, Alvarez L, et al. Quantitative effects of vegetation cover on wind erosion and soil nutrient loss in a desert grassland of southern New Mexico, USA. Biogeochemistry, 2007, 85: 317-332

75 Zuo X A, Zhao H L, Zhao X Y, et al. Spatial pattern and heterogeneity of soil properties in sand dunes under grazing and restoration in Horqin Sandy Land, Northern China. Soil Tillage Res, 2008, 99: 202-212

76 Liu C, Song X X, Wang L, et al. Effects of grazing on soil nitrogen spatial heterogeneity depend on herbivore assemblage and pre-grazing plant diversity. J Appl Ecol, 2016, 53: 242-250

77 Augustine D J, Frank D A. Effects of migratory grazers on spatial heterogeneity of soil nitrogen properties in a grassland ecosystem. Ecology, 2001, 82: 3149-3162

78 Lin Y, Hong M, Han G D, et al. Grazing intensity affected spatial patterns of vegetation and soil fertility in a desert steppe. Agric Ecosyst Environ, 2010, 138: 282-292

79 Burke I C. Spatial variability of soil properties in the shortgrass steppe: The relative importance of topography, grazing, microsite, and plant species in controlling spatial patterns. Ecosystems, 1999, 2: 422-438

80 Orwin K H, Bertram J E, Clough T J, et al. Short-term consequences of spatial heterogeneity in soil nitrogen concentrations caused by urine patches of different sizes. Appl Soil Ecol, 2009, 42: 271-278

81 Hutchings M R, Gordon I J, Kyriazakis I, et al. Sheep avoidance of faeces-contaminated patches leads to a trade-off between intake rate of forage and parasitism in subsequent foraging decisions. Anim Behav, 2001, 62: 955-964

82 Liu C. The mechanisms by grazing on grassland plant and soil spatial heterogeneity and their correlation (in Chinese). Doctor Dissertation. Changchun: Northeast Normal University, 2015 [刘晨. 放牧对草地植被、土壤空间异质性及其相互关系的调控机制. 博士学位论文. 长春: 东北师范大学]

83 Schlesinger W H, Raikes J A, Hartley A E, et al. On the spatial pattern of soil nutrients in desert ecosystems. Ecology, 1996, 77: 364-374

84 Augustine D J, Te Booth D, Cox S E, et al. Grazing intensity and spatial heterogeneity in bare soil in a grazing-resistant grassland. Rangeland Ecol Manag, 2012, 65: 39-46

85 Hirobe M, Kondo J, Enkhbaatar A, et al. Effects of livestock grazing on the spatial heterogeneity of net soil nitrogen mineralization in three types of Mongolian grasslands. J Soils Sediments, 2013, 13: 1123-1132

86 de Mazancourt C, Loreau M, Abbadie L. Grazing optimization and nutrient cycling: When do herbivores enhance plant production? Ecology, 1998, 79: 2242-2252

87 Ren H Y, Han G D, Lan Z C, et al. Grazing effects on herbage nutritive values depend on precipitation and growing season in Inner Mongolian grassland. J Plant Ecol, 2016, 9: 712-723

88 Herrero-Jáuregui C, Oesterheld M. Effects of grazing intensity on plant richness and diversity: A meta-analysis. Oikos, 2018, 127: 757-766

89 Tang Z Y, Xu W T, Zhou G Y, et al. Patterns of plant carbon, nitrogen, and phosphorus concentration in relation to productivity in China's terrestrial ecosystems. Proc Natl Acad Sci USA, 2018, 115: 4033-4038

90 Hooper D U, Vitousek P M. Effects of plant composition and diversity on nutrient cycling. Ecol Monogr, 1998, 68: 121-149

91 Knops J M H, Bradley K L, Wedin D A. Mechanisms of plant species impacts on ecosystem nitrogen cycling. Ecol Lett, 2002, 5: 454-466

92 Fu Y B, Thompson D, Willms W, et al. Long-term grazing effects on genetic variability in mountain rough fescue. Rangeland Ecol Manag, 2005, 58: $637-642$

93 Li X L, Liu Z Y, Ren W B, et al. Linking nutrient strategies with plant size along a grazing gradient: Evidence from Leymus chinensis in a natural pasture. J Integra Agric, 2016, 15: 1132-1144

94 Dijkstra F A, Pendall E, Morgan J A, et al. Climate change alters stoichiometry of phosphorus and nitrogen in a semiarid grassland. New Phytol, 2012, 196: 807-815

95 Yu R P, Zhang W P, Yu Y C, et al. Linking shifts in species composition induced by grazing with root traits for phosphorus acquisition in a typical steppe in Inner Mongolia. Sci Total Environ, 2020, 712: 136495

96 Smith S W, Woodin S J, Pakeman R J, et al. Root traits predict decomposition across a landscape-scale grazing experiment. New Phytol, 2014, 203: $851-862$

97 Zheng S X, Lan Z C, Li W H, et al. Differential responses of plant functional trait to grazing between two contrasting dominant C3 and C4 species in a typical steppe of Inner Mongolia, China. Plant Soil, 2011, 340: 141-155

98 Ritchie M E, Tilman D, Knops J M H. Herbivore effects on plant and nitrogen dynamics in oak savanna. Ecology, 1998, 79: 165-177

99 Sitters J, Cherif M, Egelkraut D, et al. Long-term heavy reindeer grazing promotes plant phosphorus limitation in arctic tundra. Funct Ecol, 2019, 
33: $1233-1242$

100 Li C L, Hao X Y, Zhao M L, et al. Influence of historic sheep grazing on vegetation and soil properties of a Desert Steppe in Inner Mongolia. Agric Ecosyst Environ, 2008, 128: 109-116

101 Gao X, Hao X, Marchbank D H, et al. Responses of herbage $\mathrm{P}, \mathrm{Ca}, \mathrm{K}$ and $\mathrm{Mg}$ content and $\mathrm{Ca} / \mathrm{P}$ and $\mathrm{K} /(\mathrm{Ca}+\mathrm{Mg})$ ratios to long-term continuous and discontinued cattle grazing on a rough fescue grassland. Grass Forage Sci, 2017, 72: 581-589

102 Moretto A S, Distel R A, Didoné N G. Decomposition and nutrient dynamic of leaf litter and roots from palatable and unpalatable grasses in a semi-arid grassland. Appl Soil Ecol, 2001, 18: 31-37

103 Bardgett R D, Wardle D A, Yeates G W. Linking above-ground and below-ground interactions: How plant responses to foliar herbivory influence soil organisms. Soil Biol Biochem, 1998, 30: 1867-1878

104 Yan L, Zhou G S, Zhang F. Effects of different grazing intensities on grassland production in China: A meta-analysis. PLoS One, 2013 , 8: e81466

105 Schönbach P, Wan H, Gierus M, et al. Grassland responses to grazing: Effects of grazing intensity and management system in an Inner Mongolian steppe ecosystem. Plant Soil, 2011, 340: 103-115

106 Maschinski J, Whitham T G. The continuum of plant responses to herbivory: The influence of plant association, nutrient availability, and timing. Am Natist, 1989, 134: 1-19

107 Heijden M G A. Mycorrhizal fungi reduce nutrient loss from model grassland ecosystems. Ecology, 2010, 91: 1163-1171

108 Tian H, Gai J P, Zhang J L, et al. Arbuscular mycorrhizal fungi associated with wild forage plants in typical steppe of eastern Inner Mongolia. Eur J Soil Biol, 2009, 45: 321-327

109 Lynch J P, Brown K M. Topsoil foraging-An architectural adaptation of plants to low phosphorus availability. Plant Soil, 2001, 237: 225-237

110 Hill J O, Simpson R J, Moore A D, et al. Morphology and response of roots of pasture species to phosphorus and nitrogen nutrition. Plant Soil, 2006, 286: 7-19

111 van der Heijden M G A, Klironomos J N, Ursic M, et al. Mycorrhizal fungal diversity determines plant biodiversity, ecosystem variability and productivity. Nature, 1998, 396: 69-72

112 Leake J, Johnson D, Donnelly D, et al. Networks of power and influence: The role of mycorrhizal mycelium in controlling plant communities and agroecosystem functioning. Can J Bot, 2004, 82: 1016-1045

113 van der Heyde M, Bennett J, Pither J, et al. Longterm effects of grazing on arbuscular mycorrhizal fungi. Agric Ecosyst Environ, 2017, 243: 2733

114 Guo Y J, Du Q F, Li G D, et al. Soil phosphorus fractions and arbuscular mycorrhizal fungi diversity following long-term grazing exclusion on semi-arid steppes in Inner Mongolia. Geoderma, 2016, 269: 79-90

115 Yang X. Mechanisms of grazing and mycorrhizal fungi affecting plant community diversity in the typical steppe (in Chinese). Doctor Dissertation. Beijing: China Agricultural University, 2018 [杨金金. 放牧与菌根真菌影响典型草原植物群落多样性的机制研究. 博士学位论文. 北京: 中国农 业大学, 2018]

116 Hinsinger P. Bioavailability of soil inorganic P in the rhizosphere as affected by root-induced chemical changes: A review. Plant Soil, 2001, 237: 173-195

117 Waddell H A, Simpson R J, Ryan M H, et al. Root morphology and its contribution to a large root system for phosphorus uptake by Rytidosperma species (wallaby grass). Plant Soil, 2017, 412: 7-19

118 Zhou Y S, Wang L Q, Zhang P, et al. Responses of the root architecture of Stipa grandis to grassland degradation (in Chinese). Pratacult Sci, 2011, 28: 1962-1966 [周艳松, 王立群, 张鹏, 等. 大针茅根系构型对草地退化的响应. 草业科学, 2011, 28: 1962-1966]

119 Song Y T, Wuyunna, Zhang F J, et al. Response of Leymus chinesnsis root morphological traits on grazing intensity-Taking Kherlen river basin steppe in Hulunbeir as study region (in Chinese). J Dalian Natl Univ, 2015, 17: 10-14 [宋彦涛, 乌云娜, 张凤杰, 等. 羊草根系形态特征对放牧 强度的响应——以呼伦贝尔克鲁伦克流域典型草原为研究区域. 大连民族学院学报, 2015, 17: 10-14]

120 Brown J H, Gillooly J F, Allen A P, et al. Toward a metabolic theory of ecology. Ecology, 2004, 85: 1771-1789

121 Enquist B J. Global allocation rules for patterns of biomass partitioning in seed plants. Science, 2002, 295: 1517-1520

122 Chen Y X, Lee P, Lee G, et al. Simulating root responses to grazing of a Mongolian grassland ecosystem. Plant Ecol, 2006, 183: 265-275

123 Brouwer R. Some aspects of the equilibrium between overground and underground plant parts. Jaarboek IBS, 1963, 213: 31-39

124 Onatibia G R, Reyes M F, Aguiar M R. Fine-scale root community structure and below-ground responses to grazing show independence from above-ground patterns. J Veget Sci, 2017, 28: 1097-1106

125 Rui Y C, Wang Y F, Chen C R, et al. Warming and grazing increase mineralization of organic P in an alpine meadow ecosystem of Qinghai-Tibet Plateau, China. Plant Soil, 2012, 357: 73-87

126 Klumpp K, Fontaine S, Attard E, et al. Grazing triggers soil carbon loss by altering plant roots and their control on soil microbial community. J Ecol, 2009, 97: 876-885

127 Gibson D J. Grasses and Grassland Ecology. Oxford: Oxford University Press, 2009 
128 van der Heijden M G A, Bardgett R D, van Straalen N M. The unseen majority: Soil microbes as drivers of plant diversity and productivity in terrestrial ecosystems. Ecol Lett, 2008, 11: 296-310

129 Bennett A E, Bever J D. Mycorrhizal species differentially alter plant growth and response to herbivory. Ecology, 2007, 88: 210-218

130 Bünemann E K, Prusisz B, Ehlers K. Characterization of phosphorus forms in soil microorganisms. In: Bünemann E K, Oberson A, Frossard E, eds. Phosphorus in Action: Biological Processes in Soil Phosphorus Cycling. New York: Springer, 2011

131 Nannipieri P, Giagnoni L, Landi L, et al. Role of phosphatase enzymes in soil. In: Bünemann E K, Oberson A, Frossard E, eds. Phosphorus in Action: Biological Processes in Soil Phosphorus Cycling. New York: Springer, 2011

132 Frossard E, Achat D L, Bernasconi S M, et al. The use of tracers to investigate phosphate cycling in soil-plant systems. In: Bünemann E K, Oberson A, Frossard E, eds. Phosphorus in Action: Biological Processes in Soil Phosphorus Cycling. New York: Springer, 2011

133 Wasaki J, Maruyama H. Molecular approaches to the study of biological phosphorus cycling. In: Bünemann E K, Oberson A, Frossard E, eds. Phosphorus in Action: Biological Processes in Soil Phosphorus Cycling. New York: Springer, 2011

134 Ibanez S, Millery A, D’ottavio M, et al. Phosphorus-rich grasshoppers consume plants high in nitrogen and phosphorus. Ecol Entomol, 2017, 42: 610-616

135 Lemoine N P, Smith M D. Drought and small-bodied herbivores modify nutrient cycling in the semi-arid shortgrass steppe. Plant Ecol, 2019, 220: 227-239

136 Torsvik V, Øvreås L. Microbial diversity and function in soil: From genes to ecosystems. Curr Opin Microbiol, 2002, 5: 240-245

137 Dijkstra F A, He M, Johansen M P, et al. Plant and microbial uptake of nitrogen and phosphorus affected by drought using ${ }^{15} \mathrm{~N}$ and ${ }^{32} \mathrm{P}$ tracers. Soil Biol Biochem, 2015, 82: 135-142

Bünemann E K. Assessment of gross and net mineralization rates of soil organic phosphorus - A review. Soil Biol Biochem, 2015, 89: 82-98 


\title{
Grazing regulation of phosphorus cycling in grassland ecosystems: Advances and prospects
}

\author{
Liji Wu ${ }^{1,2}$, Xiang $\mathrm{Li}^{2}$, Mengli Zhao ${ }^{1}$ \& Yongfei Bai ${ }^{2,3^{*}}$ \\ ${ }^{1}$ College of Grassland, Resources and Environment, Inner Mongolia Agricultural University, Huhhot 010011, China; \\ ${ }^{2}$ State Key Laboratory of Vegetation and Environmental Change, Institute of Botany, Chinese Academy of Sciences, Beijing 100093, China; \\ ${ }^{3}$ College of Resources and Environment, University of Chinese Academy of Sciences, Beijing 100049, China \\ * Corresponding author, E-mail: yfbai@ibcas.ac.cn
}

Grassland ecosystems, which cover a total area of 52.5 million square kilometers and account for $40.5 \%$ of the global land surface, are the largest biomes in the world. Grazing is the most dominant and direct land use type in grasslands and a predominant driver regulating multiple ecosystem functions and services, such as primary production, nitrogen (N) and phosphorus $(\mathrm{P})$ cycling, carbon sequestration, forage and food production, and water and soil erosion control etc. Many studies have demonstrated that primary production of grasslands is often limited by water, $\mathrm{N}$ and $\mathrm{P}$ availability, which interact with grazing to influence the maintenance of ecosystem functions and services. However, compared with numerous studies on the effects of grazing on $\mathrm{N}$ cycling and plant water use, fewer studies have explored how grazing influence $\mathrm{P}$ cycling of grasslands, particularly the internal cycling of $\mathrm{P}$ among main pools within ecosystems. Here we reviewed the advances in grazing effects on soil and plant $\mathrm{P}$ pools and biological processes of $\mathrm{P}$ cycling. Our review is mainly focused on: (1) Grazing effects on internal and external cycles of P in grassland ecosystems; (2) grazing effects on soil P vertical distribution, and $\mathrm{P}$ inputs and outputs mediated by soil erosion and spatial heterogeneity; and (3) mechanisms underlying grazing-induced changes in plant $\mathrm{P}$ content and $\mathrm{P}$ pools across different levels of organization (individual, species, functional group and community). Finally, we proposed a unified framework synthesizing the influence of grazing on $\mathrm{P}$ pools and key biological processes of $\mathrm{P}$ cycling in grassland ecosystems. We also proposed eight key questions that need to be addressed in future studies: (1) How do the dominant P forms (e.g., nucleic acids, phospholipids, cytoplasmic inorganic $\mathrm{P}$, cytoplasmic organic $\mathrm{P}$, and polyphosphate) and concentration within soil microbial biomass vary with grazing intensity? How does the role of microorganisms as sink and source of P change with increasing grazing intensity? (2) How does grazing affect enzyme activities, including phosphomonoesterases, phosphodiesterases, triphosphoric monoester hydrolases, and enzymes acting on phosphoryl-containing anhydrides and on $\mathrm{P}-\mathrm{N}$ bonds, and thereby $\mathrm{P}$ mineralization in soil? (3) How does grazing regulate the biological processes of $\mathrm{P}$ transformation in plant-soil-microbial P cycle? (4) To what degree molecular approaches and omics analyses can improve our understanding of the important role of plants and rhizosphere microorganisms in P cycling? (5) How does grazing affect the relationship between plant diversity and arbuscular mycorrhizal fungi (AMF) diversity, and thereby plant $P$ uptake and utilization? (6) How do grazing animals differ in their effects on the pools and pathways of $\mathrm{P}$ cycling due to the interspecific differences in diet and foraging preference? (7) How do other herbivores in terms of grasshoppers, rodents, earthworms, and plant feeding nematodes influence the biological processes of P cycling? (8) How does grazing affect the N:P stoichiometry of key ecosystem compartments, and hence the coupled $\mathrm{N}$ and $\mathrm{P}$ cycles.

grazing system, phosphorus (P) cycling, $\mathrm{P}$ content, $\mathrm{P}$ pool, N:P ratio, $\mathrm{P}$ limitation

doi: 10.1360/TB-2020-0321 